Greener Governments: Partisan Ideologies, Executive Institutions and Environmental Policies

\author{
Justin Leinaweaver \\ Department of Political Science \\ Drury University \\ Springfield, MO USA \\ Robert Thomson \\ School of Government and Public Policy \\ University of Strathclyde \\ Glasgow, UK
}

Corresponding Author:

Justin Leinaweaver

jleinaweaver@drury.edu

Drury University

900 N Benton Ave

Springfield, MO 65802

USA

Accepted for publication in Environmental Politics, December 2015 


\title{
Greener Governments: Partisan Ideologies, Executive Institutions and Environmental Policies
}

\begin{abstract}
Why do some governments have more environmentally friendly policies than others? Part of the answer involves governing parties' ideological positions on environmentalism and the constraints imposed by executive institutions. This paper elaborates this party-based explanation and tests it with uniquely comparable indicators of national environmental policies for governments in 27 countries in the European Union. The findings show that governments with parties that emphasized environmental protection in their manifestos are more likely to propose pro-environment policies during EU-level negotiations. However, the effect of ideology is mediated by the centralization of the national executive branch. In centralized national executives the environmental positions of prime ministers' parties affect policies, while in decentralized national executives the positions of environment ministers' parties are relevant. The findings have implications for understanding the impact of parties' environmental positions on government policies, as well as for policymaking in coalitions more generally.
\end{abstract}

Keywords: Environmental policy, Ideology, Ministerial autonomy, European Union, Political parties Word Count: 8,563 (excluding title page and appendix)

This study examines the impact of political parties' attention to environmental protection on governments' policy outputs. Parties have responded to environmental problems and public concern for the environment by devoting attention to this theme in their electoral appeals, although the extent to which they have responded has varied across parties and elections (Müller-Rommel 2002; MüllerRommel and Poguntke 2002; Carter 2013; Cao, Milner, Prakash and Ward 2014; Spoon et al. 2014). Environmentalism is now a salient electoral issue and part of a new dimension of politics (Rohrschneider 1993; Hooghe et al. 2002). The question we ask is, under what conditions do governments adopt policies to protect the environment when parties that espouse support for the environment are in office? It is clearly not always the case that governments do so. Despite the commitment to environmental protection by mainstream parties in France, Germany and the UK in the mid 2000s, these governments' commitment to environmental protection waned at the global climate change conference in 2009. So whether mainstream parties' commitment to the environment is more than "a passing fad" of little consequence for policy is an apt question (Carter 2013, p.90).

The extent to which governing parties follow through on the commitments they made during previous 
election campaigns is also relevant to many strands of democratic theory, which posit that citizens have indirect control over public policies through elections and parties (Dahl 1991; Mansbridge 2003). Election results give certain parties or combinations of parties the potential to form governments, which in turn should shape the ideological makeup of governments and the policies they pursue. Responsible parties that enter government have the ability and obligation to implement the principles they supported during the previous election campaign. This idea is a prominent feature of the mandate theory of democracy and the responsible party model (Downs 1957; Klingemann et al. 1994; Powell 2000), which set out a democratic chain of command and control through which voters influence public policies. Party ideologies are an important part of this chain, because voters rely on them as cognitive devices to simplify the complexity of politics (Van der Eijk et al. 2005). Consequently, democratic theorists expect there to be a correspondence between governing parties' ideological positions and governments' policies.

We offer theoretical and empirical contributions to research in this area. With respect to theory, we develop propositions about the conditions under which parties' ideological positions, in particular the strength of their commitment to environmental protection, affect government policies. These propositions focus on the distinction between the positions of the party of the prime minister and of the environment minister, which may differ in coalition governments, as well as the degree of centralization of the executive branch. In doing so, we seek to identify the conditions under which parties matter for policymaking (Schmidt 1996; Guinaudeau 2014), rather than simply asking whether parties matter. The specific institutional context on which we focus, the centralization of the executive branch, has received relatively little attention until now.

Our empirical contribution is to examine the impact of parties' environmentalism on a set of uniquely comparable indicators of national governments' policies on environmental issues. We examine the policy positions taken by national governments of the member states of the European Union in EUlevel negotiations. This arena offers a set of observations in which national governments composed of parties with markedly different policy positions and domestic institutional arrangements (our key independent variables) take positions on the same specific policy issues (our dependent variable).

Most previous analyses of governments' environmental policies, as well as studies of other policy 
areas, were unable to draw on such directly comparable indicators, and instead focused on aggregate indicators of policy outcomes such as greenhouse gas emissions (e.g. Neumayer 2003; Scruggs 2003; Jensen and Spoon 2011). These studies have revealed important insights. Jensen and Spoon (2011) for example find that governments that are more pro-environment and cohesive make more rapid progress toward their environmental targets than less pro-environment and cohesive governments. Outcomes are of primary concern to policymakers and citizens, but policy outputs are of primary relevance to theories of the effects of the partisan composition of government office (Knill et al. 2010, p. 302). Outcomes such as levels of emissions are likely to be influenced by a range of factors other than the policies of national governments, including the behavior of citizens and industries.

Our work also differs from other related research that is based on aggregate indicators of policy outputs and/or relatively small numbers of observations. Some of this work has demonstrated that the ideological positions of governments and legislators affect government policies (e.g. Ward and Cao 2014). Knill et al. (2010) examine evidence consisting of 96 observations of the number of environmental measures adopted by governments in 18 OECD countries at four time points. They find that the number of environmental measures increases when the policy positions of governing parties are more pro-environment. Their evidence also suggests that the existence of a ministerial portfolio that deals exclusively with environmental issues is associated with a greater number of environmental measures. Building on the work of Tosun (2014), Bäck et al (2015) focused on the adoption of bans on the cultivation of GMO crops in EU member states. They found that such bans were more likely when Christian Democratic parties were in office, and particularly when they held the relevant ministerial portfolio. An unavoidable limitation of their study is that fact that there were relatively few such bans: ten in total. The fact that they found significant effects may indicate that the magnitude of such partisan variables could be substantial. Our research design is distinct in that it offers more information than previous quantitative studies on the substantive policies adopted by each government in our sample compared to other governments; we are able to rank governments relative to each other on the same specific policy issues. Moreover, the fact that we examine a greater number of observations enables us to test more refined mechanisms concerning the allocation of ministerial portfolios and executive institutions than has been possible until now. 
By focusing on national governments' policy positions on proposed EU laws, our study also relates to research on governments' policies on international environmental agreements. In a previous study in this journal, Schulze (2014) demonstrated that governments composed of parties that place a greater emphasis on environmental protection were more likely to ratify global environmental agreements. While this is an important finding, the ratification of global agreements is not the strongest test of the impact of partisanship. Downs et al. (1996) observe that states comply with international agreements because they require activities that states would have performed on their own, or because compliance requires little policy change. In contrast, by focusing on national governments' policy positions on controversial issues raised by proposed EU laws, we examine situations in which the collective decision is rarely in line with the national policy positions of all member states. This means that at least some member states are likely to have to change their national policies. Moreover, compared to international agreements, the EU has a well-developed set of compliance mechanisms at the supranational level, including the European Court of Justice. This offers a compelling test of the impact of parties' environmental positions on national governments' policies.

\section{How Parties' Environmentalism Affects Government Policies}

Ideology is commonly defined as a set of principles that help people to interpret the world as it is and how it should be (Denzau and North 2000, 24). We conceive of parties' commitment to environmental protection as a component of their ideological positions, and differences among parties in this respect as a question of degree rather than type. This conception of parties' environmental positions is akin to the spatial conception of ideology that distinguishes among parties by their positioning on one or more dimensions that summarize the ideological principles to which they adhere (Downs 1957). Although parties take positions on ideological dimensions in line with their historical and societal origins, they may shift positions in the process of party competition and internal party politics. The spatial approach has been dominated by references to the generic left-right dimension. The content of the left-right dimension differs among political systems, but it commonly characterizes differences of principle on the appropriate role of the state in society. Some analyses distinguish between an economic or socioeconomic left-right dimension, which refers mainly to state intervention in the economy, and the social left-right dimension, which refers to state intervention on moral issues. Hooghe et al. (2002) argue that green politics is part of a new dimension of ideological contestation: the distinction between 
green, alternative and libertarian principles (GAL) on the one hand and traditional, authoritarian and nationalist principles on the other (TAN).

The party family approach to ideology, by contrast, implies that ideology is a categorical variable. The family approach distinguishes among parties by the family types to which they belong: as well as green parties, conservative, social democratic, liberal, etc. (Lipset and Rokkan 1967; Mair and Mudde 1998). The family approach captures differences and similarities among parties in terms of their principles, historical development and societal origins. With respect to green parties, the family approach highlights the distinct origins of many green parties in peace, anti-nuclear and feminist movements (Müller-Rommel and Poguntke 2002). If we follow the general principle of maximizing variation on our independent variable, then the spatial approach is preferable because it offers more nuanced variation in ideological positioning. ${ }^{1}$

The spatial approach to ideology is particularly appropriate when examining the impact of parties' environmental positions on governments' policies on specific environmental issues. Mainstream political parties have sought to respond to environmental concerns to varying degrees (Rohrschneider 1993; Müller-Rommel and Poguntke 2002). Carter (2013) found that both left and right-wing mainstream parties emphasize environmental protection in their manifestos, and found some evidence that left-wing parties are more inclined to accommodate environmental concerns. Similarly, Spoon et al. (2014) found substantial variation among mainstream parties in the extent to which they have emphasized environmental protection in their manifestos. Mainstream left-wing parties, and mainstream parties that faced electorally successful green parties, place more emphasis on environmental protection. Our research examines whether such variation in parties' positions affects the policies adopted by governments when those parties are in office. The party family approach, by contrast, would examine differences among parties in terms of their categorization into different families, such as green, social democratic, Christian democratic and conservative. Although this is possible, as the work of Tosun (2014) and Bäck et al. (2015) demonstrates with interesting results, the limitation of the party-family approach is that it treats parties within the same family as equivalent,

1. The party family approach may be a better starting point for other research questions. For instance, if we wished to examine how ideology affects party members' sense of identity, then the family approach may be preferable. 
while we know that they differ markedly in the degree of their commitment to environmental protection. In addition, there are relatively few cases of genuinely green parties entering government office, despite recent examples in the Czech Republic, Germany, Ireland and Latvia among other places. These cases of green party government participation are worthy of study in themselves (Rüdig 2006), but they are too infrequent to explain the substantial variation we observe in governments' environmental policies.

We consider the environmental positions of the parties of both the prime minister and the environmental minister, which are obviously the same in single-party governments, but may differ in coalitions. An extensive theoretical literature points to the policy influence of prime ministerial parties in multi-party coalitions (e.g. Austen-Smith and Banks 1988; Diermeier and Feddersen 1998; Dewan and Hortala-Vallve 2011). The mechanisms through which prime ministerial parties influence policy consists of their power position relative to junior coalition members, the actions they can take during the formation of a government, and the actions they can take during the course of the governing period. Prime ministerial parties in coalitions are usually the largest parties and hold the median legislator. They usually lead the formation of the coalition and the government agreement, which sets out the government's policies for the next period. Prime ministerial parties can therefore select coalition partners that are likely to produce government policies congruent with their policy preferences. Prospective prime ministerial parties also have considerable influence on the allocation and design of ministerial portfolios, which provides additional opportunities to influence government policies. One model details how prime ministerial parties can adjust the policy jurisdictions of ministerial portfolios to ensure that government policies are in line with their preferences (Dewan and Hortala-Vallve 2011). During the course of the governing period, prime ministerial parties can use the threat of votes of confidence to exert control over their junior coalition partners (Diermeier and Feddersen 1998). If prime ministerial parties hold a vote of confidence, this compels coalition partners to either accept the policy proposal of the prime ministerial party or the fall of the coalition. There are therefore ample reasons to expect the prime ministerial party's position on environmental protection to affect the government's environmental policies.

The party ideology of the environment minister is a separate explanatory variable in our model. According to the portfolio allocation model of coalition formation, the party of the minister responsible 
for any given policy area exerts most control over that area (Laver and Shepsle 1996). One of the mechanisms through which this control is exerted consists of commitment mechanisms in relation to the coalition agreement. According to the portfolio allocation model, parties will only find a coalition agreement credible if it is backed up by the allocation of ministerial portfolios, which means that the parties controlling each portfolio get to implement their own preferred policies within their ministerial jurisdictions. A distinct mechanism through which ministers exert control concerns ministerial drift (Huber and Shipan 2002, p. 185; Martin and Vanberg 2004, p. 15-6). Here, the argument is that parties have incentives to deviate from the agreements they reached with their coalition partners if those agreements do not perfectly reflect their preferences. The division of ministerial portfolios gives ministers advantages in terms of information and control over policies, which are opportunities to follow these incentives.

We posit that the effects of prime ministers and ministers on government policies are amplified or muted by the degree of centralization of the executive branch (Kassim et al. 2000; Kassim 2013). The centralization of the executive refers to coordination procedures that enable the cabinet as a whole, and the chief executive in particular, to impose coherence on government policies across different areas. While these procedures may be adjusted from time to time, they are relatively stable, institutionalized structures that tend to outlast particular governments. They encompass coordinating structures at the political and administrative levels. At the political level, relevant coordinating procedures consist of interministerial committees and/or a powerful coordinating office under the direct control of the prime minister, which enforce requirements for ministers to report to each other and the prime minister. At the administrative level, they consist of interministerial committees of senior officials. We expect the degree of executive centralization to have an important mitigating effect on the extent to which environment ministers and their parties influence the government's environmental policies. We expect environment ministers and their parties' influence to be strongest in decentralized executives and weakest in centralized executives.

Our expectations are summarized in the following propositions:

\section{Parties' positions on the environment}

1. The more pro-environmental the party of the prime minister, the stronger the government's 
environmental policies on specific policy issues.

2. The more pro-environmental the party of the environment minister, the stronger the government's environmental policies on specific policy issues.

\section{Parties' positions on the environment combined with executive institutions}

1. The influence of the prime minister's environmentalism on government policies is greater in centralized than in decentralized executives.

2. The influence of the environmental minister's ideological environmentalism on government policies is greater in decentralized than in centralized executives.

In addition to the variables referred to in our hypotheses, our analyses also include several control variables, including interdependence and economic development, which are mentioned in the research design. Some of these are particularly relevant to our testing ground, the European Union.

\section{The European Union as a Testing Ground}

The EU provides an appropriate testing ground for studying the impact of national parties' ideological environmentalism on their national governments' policy positions on specific environmental issues. We examine variation in the extent to which the national governments of EU member states take proenvironment policy positions on specific environmental issues when these issues are discussed in the Council of the EU. These specific environmental issues include funding for environmental programs, emission targets, and environmental standards for products. The fact that different governments take positions on the same specific environmental issues provides comparable observations for our dependent variable. EU member states vary considerably in the partisan composition of their governments and in their national policymaking institutions, as well as in levels of economic development. This provides variation in the explanatory variables referred to above.

We focus on legislative decision-making, which takes place in the context of inter-institutional negotiations involving the European Commission, the European Parliament (EP) and the Council of the EU. In this study we concentrate on the Council, in which member states are represented. However, the analyses also take into account the policy positions of the European Commission and the EP. 
The Council is divided into sectoral Councils that focus on different policy areas. Given our focus on environmental policymaking, many of the specific policy issues we select were discussed partly or exclusively by the environment configuration of the Council of the EU. However, other configurations of the Council also discussed policy issues that raised environmental concerns. For instance, the fisheries ministers regularly considered conservation issues. Each configuration of the Council is affected by other parts of the Council, both horizontally and vertically. This gives environment ministers the opportunity to monitor and influence their fellow national ministers' behavior in other configurations of the Council. Below the ministerial level, many committees prepare ministers' decisions. The Committee of Permanent Representatives (Coreper) sits at the top of this committee structure and provides for a degree of horizontal integration. Below this, there are many working groups composed of officials from each country. These officials are either based in their member states' permanent representations to the EU or in relevant national ministries. Legislative proposals are passed up and down the Council hierarchy during the decision-making process. Lower level committees may pass an issue they were unable to resolve upwards. Ministers may agree the general contours of a settlement and instruct lower level committees to work out the details. This complexity of the Council in terms of the multiple pathways of influence means that it provides a demanding test of the effect of partisan ideology on governments' policy positions.

\section{Research Design}

The data for our dependent variable -- governments' policy positions on specific environmental issues - are taken from the Decision-making in the EU (DEU) project (Thomson et al. 2006; Thomson et al. 2012). The DEU project examined 331 controversial issues from 125 legislative proposals from a range of policy areas, and we base our analyses on 55 of these issues from 27 proposals that raised environmental concerns and on which we have data on our explanatory variables. ${ }^{2}$ The DEU project selected only those legislative proposals that carried at least some political importance and controversy, that were subject to either the consultation or the codecision procedures and from only those that arrived on the Council's agenda in the years 1999 and/or 2000, or were discussed for the first time in

2. Table A.1 in the online appendix gives a summary of the environmental issues raised in these legislative proposals. When a legislative proposal raised both environmental and non-environmental issues, we included the environmental issues and excluded the non-environmental ones. 
the Council after the 2004 enlargement.

For each of these legislative proposals, the DEU researchers conducted semi-structured interviews with key informants to describe the controversial policy issues that each proposal raised and each of the main decision-making actors' positions on each policy issue. The data on the 55 environmental issues we examine here were collected in 103 semi-structured interviews, which lasted an average of 60 minutes. Most of the interviewees (72) were officials from member states' permanent representations and included a balance of northern and southern, as well as old and new member states. The remaining interviewees were officials from the Commission (22) and the EP (9). The interviews on each proposal were held when the proposal was being discussed in the Council or soon afterwards. To elicit the positions of member states on each specific policy issue, key informants were presented with a list that included all member states and were asked to 'indicate the policy alternative initially favored by each stakeholder after the introduction of the proposal and before the Council formulated its common position.' During the course of these semi-structured interviews, each issue was represented in the form of a policy scale, ranging from 0 to 100 , which referred to the most extreme positions taken on the issue. $^{3}$

The units of analysis are member states' positions on each controversial issue. Of the 55 policy issues selected, 17 were raised by legislative proposals that were introduced in the years prior to 2004, when the EU had 15 member states; 10 of the policy issues were raised in the years 2004 to 2006 when the EU had 25 members; and the remaining 28 policy issues were raised by legislative proposal introduced after the 2007 enlargement when the EU expanded to 27 members (all were discussed before the EU enlarged to 28 members with the accession of Croatia in 2013). Not all member states took positions on all issues, either because they were unable to form a coherent national position or because they were indifferent. Taking into account missing data on our dependent and independent variables, we have 909 observations in our analyses.

\section{[ INSERT TABLE 1 ]}

3. Tests to compare the informants' judgments with information from Council and EP documentation and with the estimates of different informants support the validity and reliability of these estimates (Thomson et al. 2006, 329-47). In addition, König et al. (2007) compared 31 point estimates provided by key informants from the Council with estimates from informants in the EP and found that 30 match perfectly or almost perfectly. 
Table 1 contains information on actors' positions on the policy issues raised by the proposal on waste (COD/2005/281). This proposal was introduced by the Commission to ensure a harmonized EU-wide system of dealing with household waste. One of the controversial policy issues related to the classification of waste incinerators as either recovery operations or disposal operations. This distinction is important because waste recovery operations are permitted to handle imported waste and also go towards meeting recovery targets set by other EU legislation. As mentioned above, during the data collection each policy issue was represented as a scale from 0 to 100 . The environmental issues were coded so that position 100 on the scale is the 'greenest' position. On the incineration issue, the green position is that incineration should not be classed as recovery under any circumstances. At the opposite end of the scale, on position 0 , is the 'brown' position that most incinerators could be classed as recovery operations. Three other alternatives were put forward, and key informants placed these between the outlying positions to reflect the political distances between them. The main political difference was between the EP that favored the continuation of the status quo, which meant that no incineration is classed as waste (position 100), and member states and the Commission that wished to classify incineration as recovery at least if certain conditions were met. The outcome was more in line with the positions of the member states and Commission than with the position of the EP.

The second issue in Table 1 refers to a disagreement on whether the EU should impose waste prevention targets on member states. The structure of the positions is similar in that the EP took the strongest environmental position, while the Commission and member states took either the weakest environmental position or intermediate positions. The third issue concerns the question of whether the EU should impose targets for recycling. Here, the actors divided into two groups. The first group, which consisted of the Commission and 20 member states, argued against targets for recycling. We describe this as the weakest environmental position. The second group, which consisted of the EP and five member states, argued for the introduction of such targets. We describe this as the strongest environmental position.

We construct a three-category ordinal variable as our dependent variable. This variable identifies whether the member state in question took the weakest environmental position (which is always position 0 on our policy scales), an intermediate position (between 0 and 100) or the strongest 
environmental position (which is always position 100 on our policy scales). ${ }^{4}$ A recent simulation-based study examined the effects of measurement error in the DEU dataset on the robustness of inferences regarding the predictive accuracy of alternative decision models (Leinaweaver and Thomson 2014). It argued that analyses should take into account the clustering of actors' positions into distinct groups, as we do in the present study. Moreover, our three-category operationalization avoids making direct comparisons of say a 50 on one policy scale with a 60 on another scale. Instead, our dependent variable treats these values as equivalent in that they are both 'intermediate' positions.

The main explanatory variables in our analysis include the ideological environmentalism of prime ministers and environment ministers' parties. For these variables we use data from the Comparative Manifestos Project (CMP; Klingemann et al. 2006). The CMP dataset contains information on the percentage of each party's manifesto or proxy document, such as a leaders' campaign speech, devoted to each of 56 thematic categories. The documents are unitized to divide them up into sentences or quasi-sentences. Human coders categorized each unit into one of the 56 categories. The category on which we focus is 'Environmental Protection: Positive' (theme 501), which has been used as an indicator of parties' commitment to environmental protection in several previous studies cited earlier (Knill et al. 2010; Carter 2013; Spoon et al. 2014). This category is reserved for sentences or quasisentences that refer to 'General policies in favor of protecting the environment, fighting climate change, and other 'green' policies. For instance: General protection of natural resources; Preservation of countryside, forests etc.; Protection of natural parks; Animal rights.' For each case, we take the CMP measures of the ideological environmentalism of the prime minister and environment minister's parties for their manifestos immediately prior to the date on which the legislative proposal was introduced. The original CMP measures are highly skewed. We therefore take the natural log of these original measures, after adding one so as to obtain values for parties that devote none of their manifesto to environmentalism and to avoid the steepest part of the logarithmic function between zero and one (See Table A.2 of the online appendix for descriptive statistics). ${ }^{5}$ As part of our robustness tests, we apply Benoit et al's. (2009) approach to modeling uncertainty in CMP estimates and find that our results hold.

4. Figure A.1 in the online appendix illustrates the distribution of the original positional variable and the three-category ordinal variable we use.

5. Our measures of the ideological environmentalism of the prime ministerial and environment ministerial parties are not highly correlated $(\mathrm{r}=.34)$. We also perform separate analysis on the cases in which the ideological environmentalism of the prime minister's and environment minister's parties differ. 
To measure the centralization of the executive branch, we refer to Kassim's (2013) typology, which draws on his and other researchers' qualitative work on the organization of national executives with respect to the interaction between national governments and the EU (e.g. Kassim et al. 2000; Laffan 2006; Gärtner et al. 2011). Kassim (2013) distinguishes between centralized and decentralized executives with respect to the distribution of power among different departments. Centralized governments constrain individual ministers with a range of mechanisms, including the presence of a clear coordinating role for the prime minister's office, interdepartmental committees and a strong permanent representation of the member state to the EU. According to Kassim (2013), the following states have decentralized executives: Austria, Belgium, Bulgaria, Cyprus, Estonia, Germany, Greece, Hungary, Italy, the Netherlands, Romania, Slovakia and Slovenia. The other 14 member states of the EU-27 (before the 2013 enlargement with Croatia) have centralized executives. ${ }^{6}$

Our control variables incorporate the effects of interdependence, in the sense that the policy of any given government may depend on the policies of other governments and European institutions. We count the number of member states (excluding the member state in the case in question) that took the strongest environmental position on each issue. This variable has a value of zero for all states on the issues of waste incineration and waste prevention targets (Table 1), since only the EP took the strongest environmental position. On the issue of recycling, it has a value of five for all states with the exception of Belgium, Denmark, Italy, Portugal and Spain, for which it has a value of four. Excluding the member state referred to in the dependent variable in each case from the count of strongest environmental positions ensures we do not include the same information on both sides of the equation in our statistical model. We also include variables that control for whether the Commission and EP took the strongest environmental position. These do not feature in our expectations, but are appropriate control variables in the context of EU decision-making. We also control for GDP per capita, since we expect states with higher levels of GDP to have more environmentally friendly policies. We employ Eurostat data on GDP per inhabitant in Euros in the year in which the legislative proposal in question was introduced. The GDP data are divided by 1,000 and are in 2009 prices. The GDP per capita variable is also skewed, and we therefore take the natural $\log$ of it.

6. Kassim (2013) also distinguishes among systems on the basis of whether their coordination ambition is comprehensive or selective, which indicates whether or not coordination is confined to nationally salient issues. Since all our cases refer to controversial issues, they are nationally salient to at least some extent; we therefore do not include this second dimension. 


\section{Analysis}

Multinomial logit models are presented in Table 2 rather than ordered logit models because the data violate the parallel regression assumption of ordered logit. ${ }^{7}$ The coefficients estimate the effect of changes in the explanatory variables on the likelihood that states take intermediate versus weak environmental positions ( 1 vs. 0 ) and strong versus weak environmental positions ( 2 vs. 0 ).

Model 1 in Table 2 includes only the direct effects of the environmentalism of prime ministers and environment ministers' parties, without controlling for the degree of centralization in the government executive. A comparison of the effects with those found in Model 2, which does include executive centralization, demonstrates the importance of including this executive institution. The effect of prime ministerial parties' environmental positions is smaller, although still positive and significant, in Model 1, compared to the conditional effect in Model 2, which does include this variable. Specifically, in Model 1 the coefficient referring to the effect of prime ministerial parties' environmentalism on the likelihood that governments take strong versus weak policy positions is .52 (s.e. $=.22, p=.02$ ). In Model 2, this effect is .89 (s.e. $.30, p=.00$, combining the direct effect of .04 and the conditional effect of .85 and recalculating the relevant standard error). A similar and even stronger pattern is evident regarding the effects of environment ministers' parties. Model 1 does not provide any evidence that environment ministers' parties affect policy. Only when executive centralization is included is it apparent that environment ministers have a marked effect on government policy in decentralized executives. Model 2 indicates that in decentralized executives, environment ministers' environmental positions significantly and positively affects the likelihood that the government takes both an intermediate versus a weak (1 vs. 0) and a strong versus a weak (2 vs. 0) policy. In centralized executives, environment ministers' parties do not have a significant effect on governments' policy positions.

\section{[ INSERT TABLE 2 ]}

\section{[ INSERT FIGURE 1 ]}

7. The Brant Test was applied to the ordered logit version the second model in Table 2, and this indicated that the parallel regression assumption was violated $\left(\mathrm{X}^{2}\right.$ for all coefficients together of $\left.256.24, \mathrm{p}=00\right)$. 
The magnitudes and significance of the effects from Model 2 are depicted in Figure 1. In line with the above interpretation, the effect of the prime ministerial party's environmental positions is positive and differs significantly from zero in centralized systems for the comparison between the strongest and weakest government policies. In decentralized systems by contrast, there is no effect of the prime ministerial party's environmental positions. The opposite is true of the effects for environment ministers. Environment ministers' positions also affect the likelihood that governments adopt intermediate versus weak environmental policies. Figure 1 adds that for both prime ministers and environment ministers there is a significant difference between their effects in the two domestic institutional contexts of centralized and decentralized executives with respect to the likelihood that governments adopt she strongest versus the weakest environmental policies.

The effects found in Model 2 are depicted as predicted probabilities in Figure 2, holding other variables constant at their means (for continuous variables) or modes (for dichotomous variables). Figure 2 shows that for a state with a centralized executive and prime ministerial party with the lowest level of commitment to environmental protection (a value of 0 ), the probability it takes the weakest environmental position on a specific environmental issue is .64 . This probability falls to .37 for a similar state with a prime ministerial party with the highest observed level of commitment to environmental protection (a value of 2.6 or approximately $13 \%$ of the manifesto focused on "environmental protection"). At the same time, the probability of taking the strongest ideological position on a specific environmental issue increases from .07 to .40 . In other words, states with centralized executives and prime ministerial parties with low levels of commitment to environmental protection are more likely to take weak than strong environmental positions on specific issues. By contrast, if those states have prime ministerial parties with strong pro-environment positions, they are just as likely to take strong rather than weak environmental positions on specific issues.

\section{[ INSERT FIGURE 2 ]}

Figure 2 depicts a similar pattern for the effect of environment ministers in states with decentralized executives. At the lowest level of commitment to environmental protection observed in our sample (a value of 0 ), the probability that such a state takes the weakest environmental position on a specific 
issue is .76, while the probability of taking the strongest position is a minuscule .05 . By contrast, if a state with a decentralized executive has an environment minister whose party has the strongest proenvironment position (a value of 3.82 or approximately $44 \%$ of the manifesto focused on "environmental protection"), then the probability it takes the strongest environmental position on a specific issue leaps to .37 , rising above the probability that such a state would take the weakest environmental position on a specific issue $(.33) .^{8}$

Table 2 also contains Models 3 and 4, which divide the sample into cases in which the prime minister and environment minister were from the same party (Model 3) and cases in which they were from different parties (Model 4). Model 3 therefore includes only the ideological position of the prime ministerial party, since this is identical to that of the environment minister's party. The effect of this variable, which is positive and significant with respect to the likelihood that governments take strong versus weak ( 2 vs. 0 ) policy positions, is therefore the combined effect of both prime ministers and environment ministers. The results of Model 4 are more relevant to our propositions regarding the conditional effects of executive centralization and are similar to those of Model 2. The effect of prime ministers' parties on the strong versus weak comparison of policy positions is positive and significant in centralized executives $(b=1.70$, s.e. $=.63, p=.01$, combining the direct and indirect effects in Model 4), but insignificant in decentralized executives. Meanwhile, the effect of environment ministers' parties on the strong versus weak comparison of policy positions is positive and significant in decentralized systems, but insignificant in centralized systems $(b=.40$, s.e. $=.51, p=.43$, again combining the direct and indirect effects).

We tested the robustness of our findings to different model specifications and present the most important of these in more detail in the online appendix. Our main findings concerning parties' ideologies and executive centralization are robust to methods including the use of multilevel models to capture issue heterogeneity, tests to incorporate uncertainty in the CMP measures (Benoit et al. (2009), tests to identify whether any single state was driving the results and simulated error in Kassim's categorization of national executives as either centralized or decentralized.

8. The Italian FdV Green Federation represents the most 'ideologically environmental' party in our observations. The Italian Greens produced party manifestos that emphasized environmental protection at a consistently high level across most of the manifestos reviewed by the CMP project (up to 44\% in the mid to late 1990s). Re-estimating Model 2 from Table 2 while omitting the Italian FdV Green Federation does not significantly alter our coefficient estimates. 


\section{Conclusions}

The extent to which governing parties favor environmental protection, as measured by their electoral appeals, affects the strength of their governments' policies on specific environmental issues. This suggests that in addition to adopting green rhetoric, parties do at least, to some extent, follow through with green policies when they enter government office. Green politics is an integral part of political competition in modern democracies with mainstream parties espousing support for environmentalism to varying degrees (Rohrschneider 1993; Hooghe et al. 2002; Müller-Rommel 2002; Müller-Rommel and Poguntke 2002; Carter 2013; Cao et al. 2014; Spoon et al. 2014). Our findings add to a growing body of comparative studies that examine the effects of parties' commitment to environmental protection on governments' environmental policies (e.g. Knill et al. 2010; Schulze 2014; Ward and Cao 2014; Bäck et al. 2015).

Our work offers theoretical and empirical contributions to existing scholarship. With respect to theory, we contribute to knowledge concerning the conditions under which parties matter (Schmidt 1996; Guinaudeau 2014), and the particular condition on which we focus is the centralization of the executive, which has received little attention until now. We posited and found evidence for the proposition that in centralized executives the party of the prime minister affects policy, while in decentralized executives the party of the environment minister affects policy. This finding is relevant to theoretical and empirical work that examines the distribution of ministerial portfolios across a range of policy areas (Laver and Shepsle 1996; Goodhart 2013) and executive institutions that coordinate policies across government departments (Kassim 2005; Dewan and Hortala-Vallve 2011). Given the evidence for the impact of executive centralization, future research should continue to develop our understanding of this and related mechanisms. Lipsmeyer and Pierce's (2011) research suggests that junior ministers perform essentially the same function as the coordination mechanisms we examine. Other relevant lines of research examine the constraints imposed on ministers by legislative actors (e.g. Martin and Vanberg 2005; Strøm et al. 2010). Specifying the institutional conditions under which governing parties affect policies is relevant to environmental policies, as well as policies in other areas.

The empirical contribution was to develop a research design that offers comparable measures of governments' policies on the same specific issues. This allowed us to compare the strength of different governments' policies on the same issues and to include a large enough number of observations with 
which to examine the institutional conditions under which prime ministers' and environment ministers' party affiliations affect policies. We argued that EU environmental policy is an appropriate testing ground for our propositions. This raises the empirical question of the extent to which our findings are generalizable to other policy areas in the EU and to policies outside the EU. It has been argued that the development of policymaking at the level of the European Union has empowered national chief executives at the expense of other actors in national governments and at the domestic level (Johansson and Tallberg 2010). This might suggest that chief executives have weaker effects and ministers have stronger effects on policies in countries and policy areas outside the EU. We would therefore welcome extensions of similar research designs to other arenas with the aim of formulating and testing theoretical propositions on the conditions under which parties affect policies. 


\section{References}

Austen-Smith, David, and Jeffrey Banks. 1988. Elections, Coalitions, and Legislative Outcomes. The American Political Science Review 82 (2): 405.

Bäck, Hanna, Marc Debus and Jale Tosun. 2015. Partisanship, Ministers, and Biotechnology Policy. Review of Policy Research 32 (3): 556-75.

Benoit, Kenneth, and Michael Laver. 2006. Party Policy in Modern Democracies. London: Routledge.

Benoit, Kenneth, Michael Laver, and Slava Mikhaylov. 2009. Treating Words as Data with Error: Uncertainty in Text Statements of Policy Positions. American Journal of Political Science 53 (2): 495513.

Cao, Xun, Helen V. Milner, Aseem Prakash, and Hugh Ward. 2014. Research Frontiers in Comparative and International Environmental Politics: An Introduction. Comparative Political Studies 47 (3): 291308.

Carter, Neil. 2013. Greening the mainstream: party politics and the environment. Environmental Politics 22 (1): 73-94.

Dahl, Robert A. 1984. Modern Political Analysis. 4th ed. Englewood Cliffs, N.J: Prentice-Hall.

Denzau, Arthur T., and Douglass C. North. 2000. Shared Mental Models: Ideologies and Institutions. In Elements of Reason: Cognition, Choice, and the Bounds of Rationality, edited by Arthur Lupia, Mathew D. McCubbins, and Samuel L. Popkin, 23-46. New York: Cambridge University Press.

Dewan, Torun, and Rafael Hortala-Vallve. 2011. The Three As of Government Formation: Appointment, Allocation, and Assignment. American Journal of Political Science 55 (3): 610-627.

Diermeier, Daniel, and Timonthy J. Feddersen. 1998. Cohesion in Legislatures and the Vote of Confidence Procedure. American Political Science Review 92 (3): 611-621.

Downs, Anthony. 1957. An Economic Theory of Democracy. Boston: Addison Wesley.

Downs, George W., David M. Rocke, and Peter N. Barsoom. 1996. Is the Good News about Compliance Good News about Cooperation? International Organization 50 (3): 379-406.

Gärtner, Laura, Julian Hörner, and Lukas Obholzer. 2011. National Coordination of EU Policy: A Comparative Study of the Twelve New Member States. Journal of Contemporary European Research 7 (1): 77-100.

Goodhart, Lucy. 2013. Who Decides? Coalition Governance and Ministerial Discretion. Quarterly Journal of Political Science 8 (3): 205-237.

Guinudeau, Isabelle. 2014. Toward a conditional model of partisanship in policymaking. French Politics 12(3): 265-81. 
Huber, John D. and Charles R. Shipan. 2002. Deliberate Discretion? The Institutional Foundations of Bureaucratic Autonomy. Cambridge: Cambridge University Press.

Hooghe, Liesbet, Gary Marks, and Carole J. Wilson. 2002. Does Left/Right Structure Party Positions on European Integration? Comparative Political Studies 35 (8): 965-989.

Jensen, Christian B. and Jae-Jae Spoon. 2011. Testing the 'Party Matters' Thesis: Explaining Progress towards Kyoto Protocol Targets. Political Studies 59 (1): 99-115.

Johansson, Karl Magnus and Jonas Tallberg. 2010. Explaining Chief Executive Empowerment: EU Summitry and Domestic Institutional Change. West European Politics 33 (2): 208-36.

Kassim, Hussein. 2013. The Europeanization of Member State Institutions. In The Member States of the European Union, edited by Simon Bulmer and Christian Lequesne, 279-312. 2nd ed. Oxford: Oxford University Press.

Kassim, Hussein, B. Guy Peters, and Vincent Wright, eds. 2000. The National Co-ordination of EU Policy: The Domestic Level. Oxford: Oxford University Press.

Klingemann, Hans-Dieter, Richard I. Hofferbert, and Ian Budge. 1994. Parties, Policies and Democracy. Boulder: Westview Press.

Klingemann, Hans-Dieter, Andrea Volkens, Judith Bara, Ian Budge, and Michael McDonald. 2006. Mapping policy preferences II: Estimates for parties, electors, and governments in Eastern Europe, European Union and OECD 1990-2003. Oxford: Oxford University Press.

Knill, Christoph, Marc Debus and Stephan Heichel. 2010. Do parties matter in internationalised policy areas? The impact of political parties on environmental policy outputs in 18 OECD countries, 19702000. European Journal of Political Research 49 (3): 301-36.

König, Thomas, Bjorn Lindburg, Sandra Lechner, and Winfried Pohlmeier. 2007. Bicameral Conflict Resolution in the European Union: An Empirical Analysis of Conciliation Committee Bargains. British Journal of Political Science 37 (2): 281-312.

Laffan, Brigid. 2006. Mapping Europe from Home in Dublin, Athens and Helsinki: A Comparative Analysis. West European Politics 29 (4): 687-708.

Laver, Michael, and Kenneth A. Shepsle. 1996. Making and Breaking Governments: Cabinets and Legislators in Parliamentary Democracies. Cambridge: Cambridge University Press.

Leinaweaver, Justin, and Robert Thomson. 2014. Testing Models of Legislative Decision-making with Measurement Error: The Robust Predictive Power of Bargaining Models over Procedural Models. European Union Politics 15 (1): 43-58.

Lipset, Seymour M., and Stein Rokkan, eds. 1967. Party Systems and Voter Alignments. New York: Free Press. 
Lipsmeyer, Christine S., and Heather Nicole Pierce. 2011. The Eyes that Bind: Junior Ministers as Oversight Mechanisms in Coalition Governments. The Journal of Politics 73 (4): 1152-1164.

Mair, Peter, and Cas Mudde. 1998. The Party Family and Its Study. Annual Review of Political Science 1: 211-229.

Mansbridge, Jane. 2003. Rethinking Representation. American Political Science Review 97: 515-528.

Martin, Lanny W., and Georg Vanberg. 2004. Policing the Bargain: Coalition Government and Parliamentary Scrutiny. American Journal of Political Science 48 (1): 13-27.

Müller-Rommel, Ferdinand. 2002. The Lifespan and the Political Performance of Green Parties in Western Europe. Environmental Politics 11 (1): 1-16.

Müller-Rommel, Ferdinand, and Thomas Poguntke, eds. 2002. Green Parties in National Governments. London: Routledge.

Neumayer, Eric. 2003. Are left-wing party strength and corporatism good for the environment? Evidence from panel analysis of air pollution in OECD countries. Ecological Economics 45 (2): 203 20.

Powell Jr., G. Bingham. 2000. Elections as Instruments of Democracy. New Haven: Yale University Press.

Rohrschneider, Robert. 1993. New Party versus Old Left Realignments: Environmental Attitudes, Party Policies, and Partisan Affiliations in Four West European Countries. The Journal of Politics 55 (3): $682-701$.

Rüdig, Wolfgang. 2006. Is Government Good for Greens? Comparing the Electoral Effects of Government Participation in Western and East-Central Europe. European Journal of Political Research 45 (s1): S127-S154.

Schmidt, Manfred G. 1996. When parties matter: A review of the possibilities and limits of partisan influence on public policy. European Journal of Political Research 30(2): 155-83.

Schulze, Kai. 2014. Do Parties Matter for International Environmental Cooperation? An Analysis of Environmental Treaty Participation by Advanced Industrialised Democracies. Environmental Politics 23 (1): 115-139.

Scruggs, Lyle. 2003. Sustaining abundance: Environmental performance in industrial democracies. Cambridge: Cambridge University Press.

Spoon, Jae-Jae, Sara B. Hobolt and Catherine E. De Vries. 2014. Going green: Explaining issue competition on the environment. European Journal of Political Research 53 (2): 363-80. 
Strøm, Kaare, Wolfgang C. Müller, and Daniel Markham Smith. 2010. Parliamentary Control of Coalition Governments. Annual Review of Political Science 13 (1): 517-535.

Thomson, Robert, Javier Arregui, Dirk Leuffen, Rory Costello, James Cross, Robin Hertz, and Thomas Jensen. 2012. A New Dataset on Decision-making in the European Union Before and After the 2004 and 2007 Enlargements (DEUII). Journal of European Public Policy 19 (4): 604-622.

Thomson, Robert, Frans N. Stokman, Christopher Achen, and Thomas König, eds. 2006. The European Union Decides. Cambridge: Cambridge University Press.

Tosun, Jale. 2014. Agricultural Biotechnology in Central and Eastern Europe: Determinants of Cultivation Bans. Sociologia Ruralis 54 (3): 362-81.

Van der Eijk, Cees, Hermann Schmitt, and Tanja Binder. 2005. Left-Right Orientations and Party Choice. In The European Voter: A Comparative Study of Modern Democracies, 167-191. Oxford: Oxford University Press.

Venables, William N., and B. D. Ripley. 2002. Modern Applied Statistics with S. 4th ed. New York: Springer.

Ward, H., and X. Cao. 2012. Domestic and International Influences on Green Taxation. Comparative Political Studies 45 (9): 1075-1103. 


\section{Greener governments: Partisan ideologies, institutions and environmental policies}

\section{Online Appendix}

This online appendix provides more detail on the environmental policy issues included in the analysis (Table A.1), the descriptive statistics for the analysis (Table A.2), a graphical comparison of the original positional variable and the three-category ordinal variable we use as a dependent variable (Figure A.1) and the results of robustness tests referred to in the main text.

The first of these robustness tests, reported in Table A.3, replicates Model 2 of Table 2 using paired, multilevel logit models with random intercepts to account for the fact that our observations are nested within issues. ${ }^{9}$ While a multilevel approach is appealing because it allows us to account for the nested nature of our observations, it also carries with it additional modeling assumptions that are problematic given our data (e.g. non-independence of issues, proposals and/or states). ${ }^{10}$ The results of this first robustness test are consistent with those from our multinomial test in Table 2 although with slightly weakened significance levels, which is likely due to the much smaller number of observations in these paired logits.

Table A.4 reports the results of a second robustness test that incorporates measurement error in the CMP estimates of parties' environmentalism as estimated by Benoit, Laver and Mikhaylov (2009). These paired logit models were run using the simex package in R created by Lederer and Küchenhoff (2013) that implements the SIMEX algorithm of Cook and Stefanski (1994). ${ }^{11}$ The most relevant coefficients in these models refer to the effects of parties' environmentalism. As in the main analyses, the environmentalism of prime ministers' parties affects governments' positions in centralized executives, while the environmentalism of environmental ministers' parties matters in decentralized executives most clearly in the " 2 vs $0 "$ comparison.

\footnotetext{
${ }^{9} \mathrm{We}$ did not add a second level, that of either proposals or states, to the multilevel models in the robustness test since we have too few observations at the proposal level to justify doing so $(<30)$ and given the lack of independence that exists at the higher levels.

${ }^{10}$ Given that concern, we also re-ran the models in Table 2 with standard errors clustered by issue and found similar results.

${ }^{11}$ While it is appropriate to test the robustness of the findings to measurement error, including these measures of uncertainty involves additional assumptions, notably that there is more certainty regarding measures derived from shorter election platforms.
} 
A third robustness test was run to determine if any single state was driving our main results. Model 2 of Table 2 was run 27 times, each time dropping a single member state from the analysis while recording the estimated coefficients and standard errors for the PM, environment minister and their interaction terms with the centralization variable. The results from 26 of the 27 regressions were consistent with our main findings. The only exception was that removing Denmark from the sample pushed the significance of the interaction term with the PM's environmentalism to $\mathrm{p}<.13$.

A fourth robustness test was run to gauge the effect of possible errors in Kassim's categorization of national executives as either centralized or decentralized. Model 2 of Table 2 was run 27 times, each time assuming that one of the member states had been miscategorized along this measure of centralization. 24 of the 27 regressions maintained a significant effect for the interaction between the PM's environmentalism and centralization (exceptions being Belgium, Denmark and Italy). All 27 regressions maintained a significant effect for the environmental minister's environmentalism and only one regression, that miscategorizing Italy, pushed the significance of the interaction term with the environment minister beyond a standard significance threshold $(\mathrm{p}<.10)$.

In sum, all of these alternative specifications provide support for our main finding on the effect of parties' commitment to environmental protection on government policies: the environmentalism of prime ministerial parties positively affects on the likelihood that governments take stronger environmental positions in centralized executives, while the environmentalism of environmental ministers' parties have positive effects in decentralized executives.

\section{Additional References}

Bates, Douglas, Maechler, Martin, Bolker, Ben \& Walker, Steven. (2014). lme4: Linear mixed-effects models using Eigen and S4. R package version 1.1-5. http://CRAN.R-project.org/package=lme4

Lederer, Wolfgang \& Helmut Küchenhoff. (2013). simex: SIMEX- and MCSIMEX-Algorithm for measurement error models. R package version 1.5. http://CRAN.R-project.org/package= $=$ simex

Cook, J. R. \& L. A. Stefanski. (1994). Simulation-Extrapolation Estimation in Parametric Measurement Error Models. Journal of the American Statistical Association 89(428): 1314-1328. 
Table A.1 Fifty-Five Environmental Policy Issues from Twenty-seven Legislative Proposals

Name of legislative proposal and issues raised

The accelerated phasing-in of double hull or equivalent design requirements for single hull oil tankers (COD/2000/067)

- The speed at which single hull tankers should be phased out

Energy Efficiency Requirements for Ballasts for Fluorescent Lighting (COD/1999/127)

- The length of the transition period for phasing out inefficient lights

- The complete phasing out of inefficient magnetic ballasts

The Common Organisation of the Markets in the Sugar Sector (COD/2000/250)

- The duration of the extension of the current scheme

- The reduction of production quotas

- The abolition of subsidies for storage costs

Technical Measures for the Conservation of Fishery Resources (COD/1996/160)

- The types of nets permitted for fishing

The Common Organisation of the Market in Beef and Veal (COD/1998/109)

- The reduction of the support price

Community Structural Assistance in the Fisheries Sector (COD/1998/347)

- The scrap-build penalty to qualify for funding

- The linkage between funding and conservation objectives

Types of Behaviour which Seriously Infringe the Rules of the Common Fisheries Policy

(COD/1999/050)

- The harmonization of infringements and sanctions regarding common fisheries policy

Control Measures Applicable in the Area Covered by the Convention on Future Multilateral Co-

operation in the North-East Atlantic Fisheries (CNS/1999/138)

- The committee for implementing the regulation

Proposal for a Regulation on Production Aid for Cotton (CNS/1999/202)

- The size of the penalty for excessive production

- The level of national guarantees quantities

Establishing a Support System for Producers of Certain Arable Crops to Include Flax and Hemp Grown for Fibre (CNS/1999/236)

- The restriction of the support scheme for short flax and hemp

- The restriction of the support scheme for long flax and hemp

Conservation of Fishery Resources through Technical Measures for the Protection of Juveniles of

Marine Organisms (CNS/1999/255)

- The prohibition of fishing for sand eels in the North Sea

Regulation Concerning the Financial Instrument for the Environment (LIFE +) (COD/2004/218)

- The inclusion of nature

- The inclusion of environmental technology activities

Directive on Ambient Air Quality and Cleaner Air for Europe (COD/2005/183)

- The postponement of the deadline for targets regarding certain pollutants

- $\quad$ Targets for fine particles, PM2.5

Directive on Waste (COD/2005/281)

- The classification of incineration as recovery

- Waste prevention targets 
- $\quad$ Recycling targets

Regulation Establishing Measures for the Recovery of the Southern Hake and Norway Lobster Stocks in the Cantabrian Sea and Western Iberian peninsula

- The closure of areas for fishing

- The method of controlling fishing / how fishing effort should be measured

- The vessels that should be included

- The level of the mortality rate

Regulation Establishing Measures for the Recovery of the Sole Stocks in the Western Channel and the Bay of Biscay (CNS/2003/327)

- The type of plan to be adopted - recovery or management

- The breadth of the tolerance margin

Proposal for a regulation: European Fisheries Fund (CNS/2004/169)

- Replacement of engines

Regulation on the Common Organisation of the Markets in the Sugar Sector (CNS/2005/118)

- The size of the price cut

Directive Establishing a Framework for Community Action to Achieve a Sustainable Use of Pesticides (COD/2006/132)

- Areal spraying of crops

- The setting of targets for reducing the use of pesticides

Proposal for a regulation on modifications to the common agricultural policy (CNS/2008/104)

- The transfer of funds from CAP to rural development

- The shift of CAP funding away from production

Directive on the Promotion of Clean and Energy-efficient Road Transport Vehicles (COD/2005/283)

- The scope of application of the directive

- The amount of discretion given to member states in implementation

- The monetary value assigned to each unit of CO-2 pollution

Directive on Environmental Quality Standards in the Field of Water Policy and Amending Directive 2000/60/EC (COD/2006/129)

- The inclusion of specific measures to ensure water quality

- The list of pollutants

- The use of measures from sediment and organisms as tests for mercury, chlorine and organic chemicals

- The definition of mixing zones

Directive Amending Directive 2003/87/EC so as to Include Aviation Activities in the Scheme for Greenhouse Gas Emission Allowance Trading within the Community (COD/2006/304)

- The total amount of $\mathrm{CO} 2$ emission rights to be allocated

- Provisions for new entrants

- The start date

Regulation Setting Emission Performance Standards for New Passenger Cars as Part of the Community's Integrated Approach to Reduce CO2 Emissions from Light-duty Vehicles (COD/2007/297)

- The definition of the utility parameter

- Penalties for excess emissions

- The setting of long-term targets

- Timing of medium-term target 
Regulation on the Common Organisation of the Market in Wine and Amending Certain Regulations (CNS/2007/0138)

- Distillation

Regulation on the Protection of Vulnerable Marine Ecosystems in the High Seas from the Adverse Impacts of Bottom Fishing Gears (CNS/2007/0224)

- Depth Limit

- Observer Coverage

Directive Establishing a Framework for Community Action in the Field of Marine Environmental Policy (Marine Strategy Directive) (2005/0211/COD)

- The definition of 'good environmental status'

- The timeline for achieving good environmental status 


\section{Figure 1: The Importance of Party Ideology and Institutional Context for Envi- ronmental Position-taking}
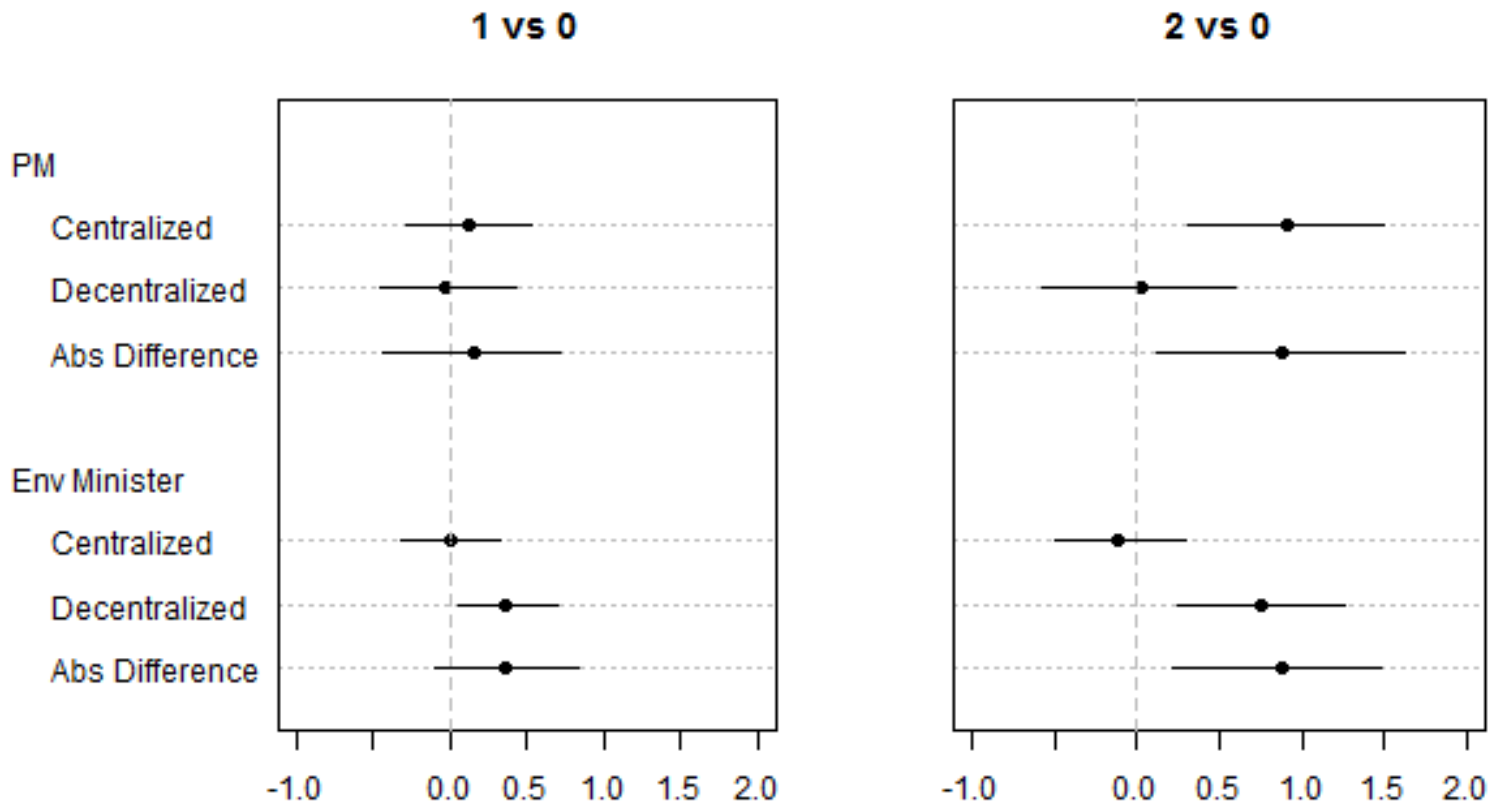

Note: Coefficients taken from Table 2, Model 2 with bootstrapped 95\% confidence intervals. The "centralized" and "decentralized" point estimates illustrate that the importance of a pro-environment ideology is contingent on institutional context. The "abs difference" line is the relevant interaction term from the model and represents a significance test of the difference between the two estimates above it. 
Table 1: Environmental Issues and Positions from the Proposal on Waste

\begin{tabular}{ll}
\hline Issues and positions & Actors \\
\hline Should the EU allow waste incineration to be classified as recovery? & \\
& \\
Least environmental position & 0: BE, FR, IT \\
0: Yes, and with low energy-efficiency requirements & \\
& 40: COM, FI, DE, EL, \\
Intermediate positions & IE, LU, NL, PT, UK \\
40-80: Yes, but with a formula including strict energy & $60:$ AT, CY, CZ, DK, \\
efficiency requirements to determine whether incineration & EE, HU, LV, LT, MT, \\
can be classified as recovery. Higher numbers refer to & PL, SI, SK, ES \\
support for stricter energy efficiency requirements & $80: \mathrm{SE}$ \\
& \\
& \\
Most environmental position & $100: \mathrm{EP}$ \\
100: Under no condition & \\
\hline
\end{tabular}

\section{Should the EU set waste prevention targets?}

Least environmental position

0: No EU obligation to have waste prevention targets $\quad$ 0: FR, DE, EL, IT, MT, PL, UK

Intermediate positions

20: MSs obliged to have targets and may determine spe-

cific qualitative or quantitative targets for programmes

30: MSs obliged to have prevention targets and shall

determine specific quantitative and qualitative targets

20: AT, CY, CZ, EE,

HU, IE, LV, LT, LU, NL,

PT, SI, SK, ES

30: COM, BE, DK, FI,

SE

Most environmental position

100: 2008 levels by 2012

100: EP

\section{Should the EU set targets for recycling?}

Least environmental position

0: No new targets

0: COM, AT, CY, CZ, EE, FI, FR, DE, EL, HU, IE, LV, LT, LU, MT, NL, PL, SI, SK, SE, UK

Most environmental position

100: $50 \%$ for household waste by 2020 and $70 \%$ for con-

struction waste by 2020

100: EP, BE, DK, IT, PT, ES

Note: (COD/2005/281). COM: Commission; EP: European Parliament; AT: Austria; BE: Belgium; CY: Cyprus; CZ: The Czech Republic; DK: Denmark; EE: Estonia; FI: Finland: FR: France; DE: Germany; EL: Greece; HU: Hungary; IE: Ireland; IT: Italy; LV: Latvia; LT: Lithuania; LU: Luxembourg; MT: Malta; NL: The Netherlands; PL: Poland; PT: Portugal; SI: Slovenia; SK: Slovakia; ES: Spain; SE: Sweden; UK: The United Kingdom. Bulgaria and Romania were not members at the time this proposal was introduced. 


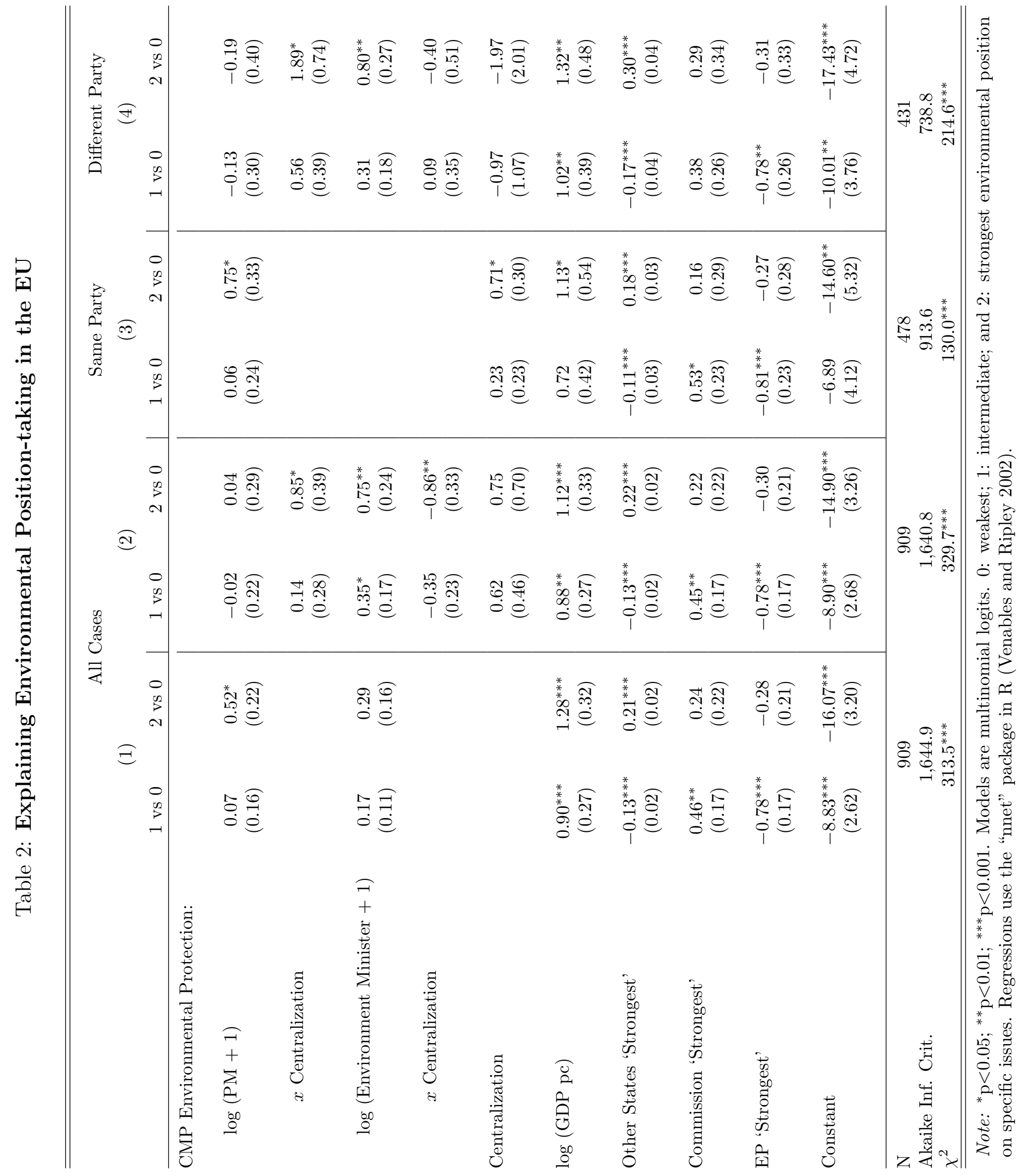




\section{Figure 2: Predicted Probabilities of Strongest and Weakest Environmental Posi- tions Under Different Conditions}

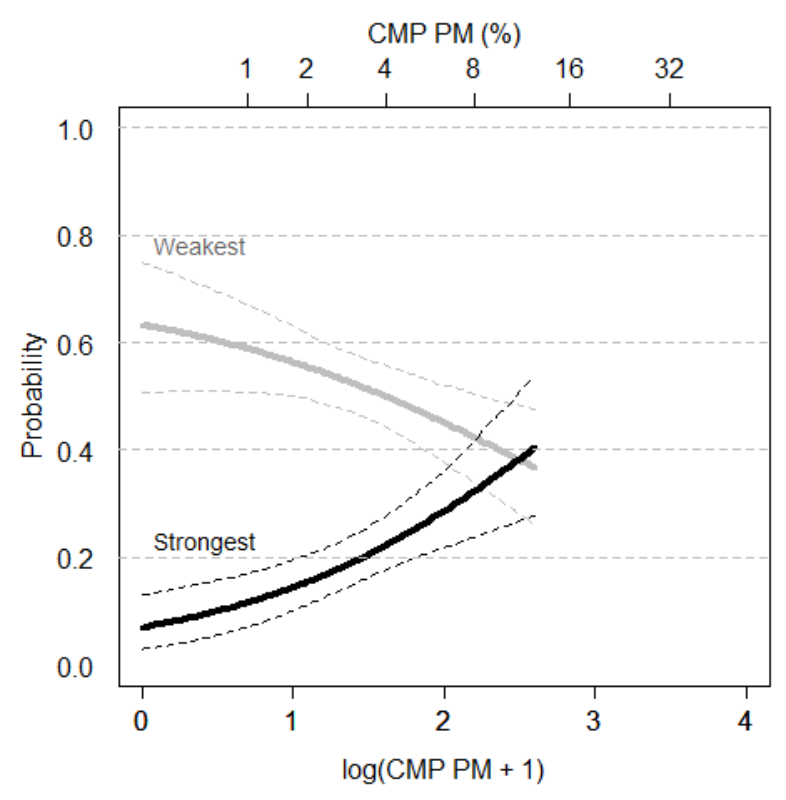

(a) Centralized Executives

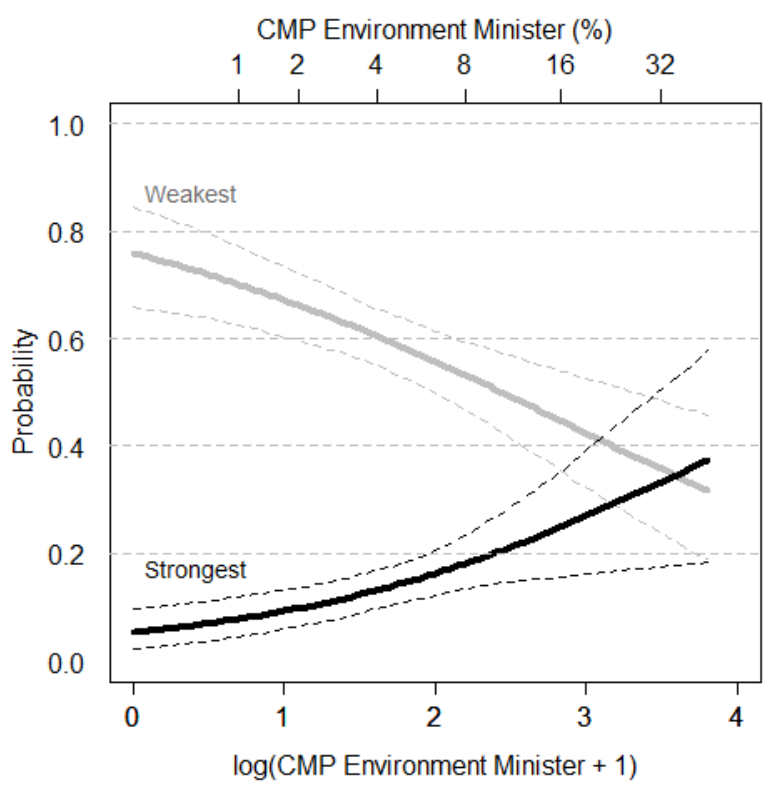

(b) Decentralized Executives

Note: Left: probabilities of governments with centralized executives taking the strongest and weakest environmental positions given prime ministers with different levels of pro-environment ideology. Right: same for governments with decentralized executives given environment ministers with different levels of proenvironment ideology. Model specified in Table 2, Model 2 with pro-environment ideology varied from lowest to highest observed values, while other variables held at their means (for continuous variables) or modes (for dichotomous variables). A bootstrap procedure is applied to estimate $90 \%$ confidence intervals. 
Table A.2: Summary Statistics

\begin{tabular}{lccccc}
\hline Dependent Variable & $N$ & Mean & sd & Min & Max \\
Environmental Position & & & & & \\
$\quad$ 0-100 Scale & 1,022 & 42.6 & 41.7 & 0 & 100 \\
& & & & & \\
$\quad$ Weakest $(\mathrm{x}=0)$ & $408(40 \%)$ & & & & \\
$\quad$ Intermediate $(0<\mathrm{x}<100)$ & $370(36 \%)$ & & & & \\
$\quad$ Strongest (x = 100) & $244(24 \%)$ & & & & \\
& & & & & \\
Explanatory Variables & $N$ & Mean & sd & Min & Max \\
CMP Environmental Protection & & & & & \\
$\quad$ PM & 1,022 & 3.7 & 2.6 & 0.0 & 12.9 \\
$\quad$ log (PM + 1) & 1,022 & 1.4 & 0.6 & 0.0 & 2.6 \\
Environment Minister & & & & & \\
$\quad$ log (Environment Minister + 1) & 1,022 & 6.1 & 6.9 & 0.0 & 44.2 \\
$\quad$ & & 1.7 & 0.7 & 0.0 & 3.8 \\
Centralization Ministerial Autonomy & 1,022 & $52 \%$ & & & \\
log (GDP per capita) & 909 & 10.2 & 0.4 & 9.2 & 11.3 \\
Other States 'Strongest' (count) & 909 & 4.2 & 4.5 & 0 & 15 \\
Commission 'Strongest' & 909 & $32 \%$ & & & \\
EP 'Strongest' & 909 & $62 \%$ & & & \\
$\quad$ & & & & & \\
\hline
\end{tabular}


Figure A.1: Dependent Variable: National Governments' Positions on Environmental Policy Issues
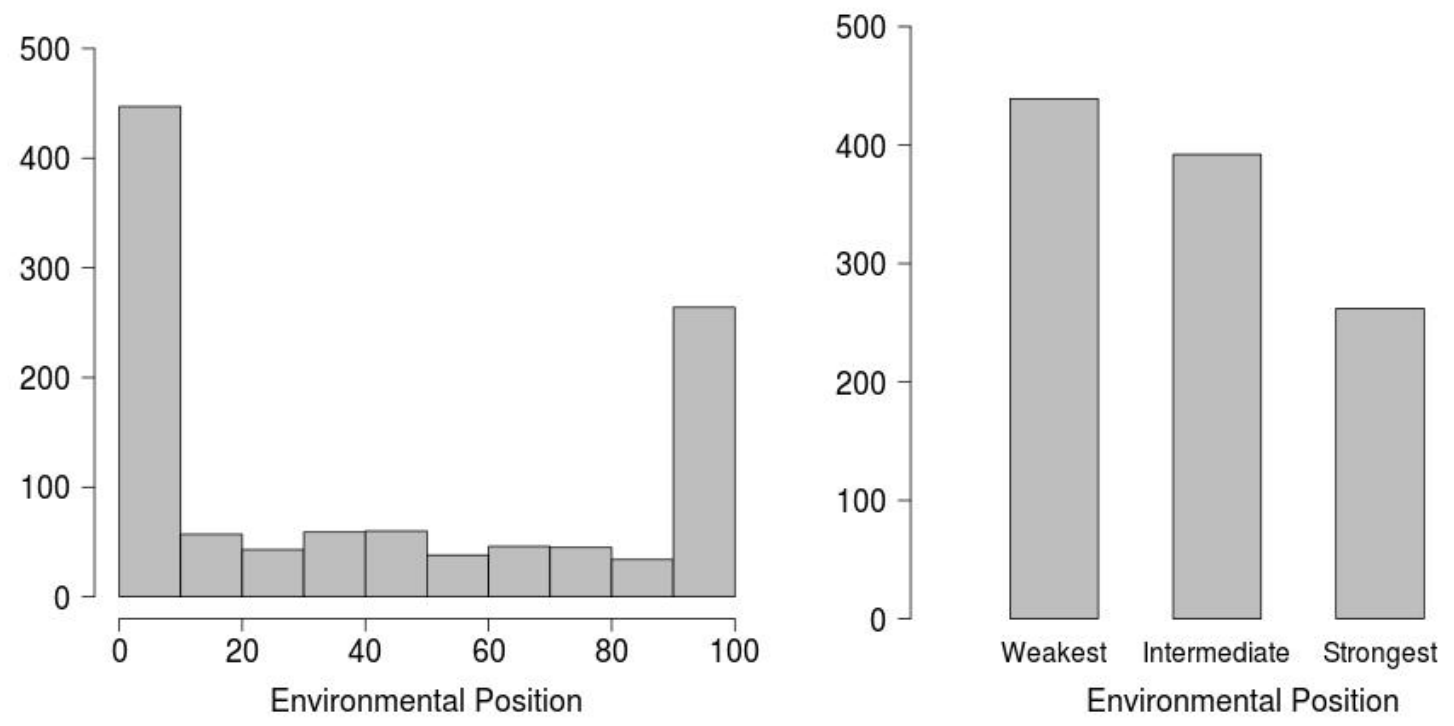

Note: Left: Distribution of governments' positions on 0-100 policy scales, on which 100 refers to the strongest environmental position. Right: Our recoding of these positions into the three-category dependent variable. 
Table A.3: Robustness Test I: Issue Heterogeneity

\begin{tabular}{|c|c|c|}
\hline & 1 vs 0 & 2 vs 0 \\
\hline \multicolumn{3}{|l|}{ CMP Environmental Protection: } \\
\hline $\log (\mathrm{PM}+1)$ & $\begin{array}{l}-0.37 \\
(0.34)\end{array}$ & $\begin{array}{l}-0.08 \\
(0.35)\end{array}$ \\
\hline$x$ Centralization & $\begin{array}{c}0.48 \\
(0.42)\end{array}$ & $\begin{array}{c}0.88^{\dagger} \\
(0.49)\end{array}$ \\
\hline $\log ($ Environment Minister +1$)$ & $\begin{array}{c}0.28 \\
(0.25)\end{array}$ & $\begin{array}{c}0.66^{*} \\
(0.29)\end{array}$ \\
\hline$x$ Centralization & $\begin{array}{l}-0.25 \\
(0.35)\end{array}$ & $\begin{array}{c}-1.01^{*} \\
(0.41)\end{array}$ \\
\hline Centralization & $\begin{array}{c}0.17 \\
(0.67)\end{array}$ & $\begin{array}{c}0.97 \\
(0.85)\end{array}$ \\
\hline $\log ($ GDP pc) & $\begin{array}{l}2.09^{* *} \\
(0.45)\end{array}$ & $\begin{array}{l}1.84^{* *} \\
(0.44)\end{array}$ \\
\hline Other States 'Strongest' & $\begin{array}{c}-0.24^{*} \\
(0.11)\end{array}$ & $\begin{array}{l}0.18^{* *} \\
(0.07)\end{array}$ \\
\hline Commission 'Strongest' & $\begin{array}{c}0.80 \\
(0.97)\end{array}$ & $\begin{array}{l}-0.16 \\
(0.57)\end{array}$ \\
\hline EP 'Strongest' & $\begin{array}{l}-1.03 \\
(0.96)\end{array}$ & $\begin{array}{l}-0.76 \\
(0.53)\end{array}$ \\
\hline Constant & $\begin{array}{c}-21.12^{* *} \\
(4.49)\end{array}$ & $\begin{array}{c}-21.43^{* *} \\
(4.32)\end{array}$ \\
\hline $\begin{array}{l}\text { Observations } \\
\text { Log Likelihood } \\
\text { Akaike Inf. Crit. }\end{array}$ & $\begin{array}{c}717 \\
-295.19 \\
612.38 \\
\end{array}$ & $\begin{array}{c}563 \\
-251.39 \\
524.78\end{array}$ \\
\hline Issue level Variance & $\begin{array}{c}9.27 \\
(3.04)\end{array}$ & $\begin{array}{c}1.99 \\
(1.41)\end{array}$ \\
\hline
\end{tabular}

Note: $\dagger \mathrm{p}<0.10 ;{ }^{*} \mathrm{p}<0.05 ;{ }^{* *} \mathrm{p}<0.01$. Paired logit models with random effects at the level of issues using "lme4" package in R (Bates et al. 2014). 0: weakest; 1: intermediate; and 2: strongest pro-environment position on specific issues. 


\section{Table A.4: Robustness Test II: Measurement Error in CMP Data}

\begin{tabular}{|c|c|c|}
\hline & 1 vs 0 & 2 vs 0 \\
\hline \multicolumn{3}{|l|}{ CMP Environmental Protection: } \\
\hline $\log (\mathrm{PM}+1)$ & $\begin{array}{l}-0.12 \\
(0.34)\end{array}$ & $\begin{array}{c}0.02 \\
(0.44)\end{array}$ \\
\hline$x$ Centralization & $\begin{array}{c}0.38 \\
(0.44)\end{array}$ & $\begin{array}{l}1.97^{* *} \\
(0.65)\end{array}$ \\
\hline $\log ($ Environment Minister +1 ) & $\begin{array}{l}0.66^{*} \\
(0.27)\end{array}$ & $\begin{array}{c}1.52^{* * *} \\
(0.38)\end{array}$ \\
\hline$x$ Centralization & $\begin{array}{l}-0.72 \\
(0.37)\end{array}$ & $\begin{array}{c}-2.08^{* * *} \\
(0.56)\end{array}$ \\
\hline Centralization & $\begin{array}{c}0.93 \\
(0.66)\end{array}$ & $\begin{array}{c}1.17 \\
(1.11)\end{array}$ \\
\hline $\log (\mathrm{GDP} p \mathrm{pc})$ & $\begin{array}{l}0.74^{*} \\
(0.33)\end{array}$ & $\begin{array}{c}0.65 \\
(0.40)\end{array}$ \\
\hline Other States 'Strongest' & $\begin{array}{c}-0.12^{* * *} \\
(0.02)\end{array}$ & $\begin{array}{c}0.26^{* * *} \\
(0.03)\end{array}$ \\
\hline Commission 'Strongest' & $\begin{array}{l}0.39^{*} \\
(0.17)\end{array}$ & $\begin{array}{c}0.41 \\
(0.25)\end{array}$ \\
\hline EP 'Strongest' & $\begin{array}{c}-0.87^{* * *} \\
(0.18)\end{array}$ & $\begin{array}{l}-0.14 \\
(0.23)\end{array}$ \\
\hline Constant & $\begin{array}{l}-7.77^{*} \\
(3.16)\end{array}$ & $\begin{array}{c}-11.78^{* *} \\
(4.00)\end{array}$ \\
\hline $\begin{array}{l}\text { Observations } \\
\text { Log Likelihood }\end{array}$ & $\begin{array}{c}717 \\
-451.0\end{array}$ & $\begin{array}{c}563 \\
-266.6\end{array}$ \\
\hline
\end{tabular}

Note: ${ }^{*} \mathrm{p}<0.05 ;{ }^{* *} \mathrm{p}<0.01 ;{ }^{* * *} \mathrm{p}<0.001$. Paired logit models that account for error in the CMP measures, as estimated by Benoit, Laver and Mikhaylov (2009). Models estimated using the SIMEX package in R by Lederer and Kchenhoff (2013) that implements the SIMEX algorithm of Cook and Stefanski (1994). 0: weakest; 1: intermediate; and 2: strongest pro-environment position on specific issues. 